\title{
LA ESCRITURA CAMALEÓNICA DE ANA LYDIA VEGA ANTE LAS PARADOJAS DEL CANON
}

\author{
POR \\ Luis ViLlamíA \\ Nazarbayev University
}

Toda la literatura puede decir larvatus prodeo, me adelanto con mi máscara.

Roland Barthes

La obra de Ana Lydia Vega ha sido en cierta medida doblegada por lecturas preestablecidas y encauzadas que cercan la multiplicidad de perspectivas que evocan sus textos. La fuerza centrífuga que configura el principio estructural de sus obras y los rasgos tan característicos de su creación (la fecunda e inagotable ironía, la actitud desacralizadora hacia temas solemnes o el virtuosismo linguístico de su peculiar estilo literario) han suscitado paradójicamente la elección de la autora como modelo y prototipo de cierta literatura contracanónica. Es curiosamente por tanto su excepcionalidad lo que en ocasiones simplifica su lectura. Como señala Guillory, los vericuetos que se derivan de la configuración del canon son ininteligibles sin la asunción del vínculo evidente que se origina entre literatura, lengua y estructura social, una trabazón mediatizada por la escuela como institución de control lingüístico (242). Es decir, el acceso de los estudiantes al repertorio de obras canónicas se fomenta porque de ellas deviene teóricamente un código "literario" especialmente sofisticado del lenguaje que incide en el habla y en la escritura, y simultáneamente (desde una lectura deshistorizada), permite instruirse en piezas artísticas con una esencia autosuficiente que trasciende el devenir del tiempo. Frente a ellas, la obra de Ana Lydia Vega se despliega en principio sobre dos directrices casi opuestas: el cultivo en su escritura, entre otras versiones lingüísticas, de un "vernáculo puertorriqueño" y la tendencia a una literatura (obviamente sólo en apariencia) intrascendente y barnizada de componente lúdico. La propia condición de la autora además - escritora y puertorriqueña- parece alentar unas coordenadas de lectura que subordinan dos de sus mayores logros: su inagotable búsqueda de la expresión original y la dimensión de alteridad que de forma tenue evocan sus obras a través de la relación intertextual que proponen sus libros con multitud de clásicos de la literatura. Por ello, con la intención de atenuar esas posibles limitaciones de lectura, quizá se 
pueda aludir aquí a la necesidad de una "hermenéutica diatópica", ${ }^{1}$ apropiándonos del término aplicado por Walter Mignolo, y del imperativo de valorar un canon como una instancia relativa a la comunidad y no tanto como una relación jerárquica respecto a un canon fundamental. En muchas ocasiones el propio mecanismo de instancias literarias genera un discurso - dotado de legitimidad- que produce conceptos y perspectivas hermenéuticas con los que, al instaurar modelos, establecen criterios de valoración excesivamente fijados. Como muy bien decía Certeau, la institución social que sobredetermina la relación del lector con el texto, no debe transformar la lectura en una literalidad ortodoxa anticipada que reduzca otras lecturas a versiones de lo herético o lo insignificante (184). Por ello, la finalidad principal de la redacción de este artículo será pretender un análisis pormenorizado del estilo literario de la autora procurando distanciarnos de ciertas pautas de interpretación más usualmente difundidas. Aspirar en cierta medida a actuar en su lectura como esos "nómadas que cazan furtivamente" (187), siguiendo la bella imagen de Certeau.

Sin duda, y así se ha hecho en ocasiones, se puede abordar la obra de Ana Lydia Vega desde unos tentadores preceptos afines siempre al concepto de "literatura menor" que enunciaran Deleuze y Guattari. Es decir, obras donde el idioma se ve afectado por un fuerte coeficiente de desterritorialización y que adquieren un valor político y colectivo de forma inherente (28-30). Ciertamente estas nociones se pueden adjudicar a su obra en mayor o menor medida, aunque sólo sea por la localización estratégica desde la que enuncia su discurso. La propia escritora, consciente de su singularidad, ironiza en uno de sus ensayos sobre su condición:

Total, es sólo una flor de minorías: mujer (aunque seamos mayoría en el planeta, ¿quién carajo se entera?); puertorriqueña (hija de esa colonia cinco veces centenari que amenaza con ser el vertedero tóxico y nuclear de Occidente); y escritora (oficio, como hemos visto, harto sufrido). (Esperando a Loló 100)

Más aún, según Ana Lydia Vega, los conflictos políticos nacionales, de eterna indefinición en Puerto Rico, no sólo impregnan la literatura de su país, sino que "siempre están en la mente del escritor que se inicia en la literatura puertorriqueña" (Kerkhoff 597). Se trata, en última instancia, de precisar y desplegar una identidad donde la presión ejercida por las convenciones, las generaciones precedentes o los estilos retóricos incitan a mimetizar un procedimiento de creación colectivo. Como señala la propia escritora:

Walter Mignolo describe así el término aquí aludido en uno de sus ensayos más difundidos citando a R. Pannikar: "es el método necesario para la interpretación cuando la distancia a salvar, necesaria para cualquier comprensión, no es simplemente una distancia dentro de una cultura única (hermenéutica morfológica) o una distancia temporal (hermenéutica diacrónica), sino más bien la distancia entre dos ( más) culturas, que se han desarrollado independientemente en espacios distintos (“Los cánones" 242).

Revista Iberoamericana, Vol. LXXIX, Núms. 244-245, Julio-Diciembre 2013, 917-927 ISSN 0034-9631 (Impreso) ISSN 2154-4794 (Electrónico)
Se trata nada más y nada menos [en el contexto de escritores en una sociedad colonia que] de encontrar eso que los críticos llaman "una voz propia". Nuestra tradición literaria, tan apegada a lo político, confunde a menudo lo individual con lo colectivo hasta tal punto que la escritura se reduce a un acto ritual de reafirmación de las raíces, de consolidación de lazos étnicos y culturales [...] De ahí también la fascinación con un vernáculo puertorriqueño que pueda ser recreado artísticamente en la página escrita, proyecto literario esencial de generaciones más recientes. (Esperando a Loló 89)

Así, la misma autora advierte la tendencia en la literatura de su país de proyectos literarios colectivos que tiñen las obras de forma casi instintiva. Pero, lejos de esta condición de estandarte, Ana Lydia Vega rechaza la necesidad de una "estética mesiánica", desafía una noción estática de identidad y otorga a la escritura una naturaleza lúdica y de aparente-sólo simulada-intrascendencia. Es más, vincula de forma paródica la asunción de una voz colectiva por parte del escritor con una predisposición a la autocensura:

[El escritor se autoimpone ser] Portavoz de la Memoria Colectiva [...]. Este quijotesco proyecto exigiría, para llevarse dignamente, una ausencia total de contradicciones, una perfecta síntesis de virtudes, algo así como una vida ejemplar. Además de un pensamiento monolítico y una vigilancia permanente sobre la eterna rebeldía de las palabras, lo que equivale a decir una autocensura a tiempo completo. (Esperando a Loló 84-85)

De esta forma, aunque es innegable y casi sustancial a su obra su mirada crítica y, utilizando sus propios términos, el cultivo de la "hiper-conciencia", estas nociones sólo se revelan integradas en la matriz de su escritura, muy cercana al concepto de simulación que elaboró Severo Sarduy. Ese "larvatus prodeo" que, según Roland Barthes, en última instancia acompaña a todo escritor (El grado cero 45), y que en Ana Lydia Vega se convierte en el cimiento sobre el que oscila toda su obra. Es una representación singular de una escritura travestida donde convergen todas las posibilidades de que dispone el mimetismo: la metamorfosis, el camuflaje y la intimidación (Sarduy 1267).

Esta simulación presente en todos los niveles de la escritura de Ana Lydia Vega no sólo devela, como señala la autora "una de las maneras más serias que conozco de hacer conflicto y es también la máscara de hierro que protege la sensibilidad en carne

El concepto de simulación de Sarduy se caracteriza sobre todo por la ausencia de modelo, el autor cubano entiende que la relación entre el modelo y la copia es una correspondencia imposible: "[...] el parecido no debe entenderse como una relación exterior; $[. .$.$] al contrario, [. .$.$] lo que los simulacros; lo que$ pretenden [es] una insinuación, una subversión, "contra el padre" y sin pasar por la Idea" (La simulació 18). Así, el fin específico de la mímesis sería la propia simulación en sí misma. Sarduy aborda este concepto analizando diferentes procesos donde se refleja la imitación, tales como la anamorfosis o el travestismo. En este último ejemplo, la aspiración última no sería por tanto transfigurarse en el otro sexo, una correspondencia de hecho imposible, sino adentrarse en una nueva región vacía donde se albergaría lo simulado.

Revista Iberoamericana, Vol. LXXIX, Núms. 244-245, Julio-Diciembre 2013, 917-927 ISSN 0034-9631 (Impreso) ISSN 2154-4794 (Electrónico) 
viva" (Ferro 7), sino que también legitima, enriquece y manipula la recepción de su obra. De esta forma, Ana Lydia Vega hereda y aplica múltiples estructuras canónicas de la literatura universal para transgredir sus significados. Avala lo que Edward Said describió como "[...] la frecuente necesidad implícita para la recepción o el reconocimiento de que un texto transporte, hasta en lo más prístino de su ser, formas consagradas" ( $E$ mundo, el texto 52). Por ello, la escritora siempre inscribe sus novelas y cuentos en un determinado horizonte teórico (ya sea a través de una relación de intertextualidad, la manipulación de géneros o la mezcla de códigos) para suscitar una expectativa de simulación en el lector y será en este espacio fronterizo donde vulnere los modos de lectura con una continua ruptura. Desde esta posición de juego irreverente, Ana Lydia Vega inserta los mecanismos de su discurso, donde en última instancia la verdadera querencia será el resultado efectista sobre el lector. Así, la forma de anular o rehace las expectativas de imitación sobre el modelo será a través del cultivo de una escritura hipertélica -apropiándonos del concepto de Sarduy-, es decir, una composición que vaya más allá de sus fines, una estética del exceso (1268).

$\mathrm{Al}$ analizar por tanto su estilo literario, esa compleja amalgama de vocablos y giros caribeños donde se integran también el inglés y el francés (González 294), la escritora no sólo busca reproducir una lengua oral, sino que esa contaminación del "vernáculo puertorriqueño" del discurso escrito capta, como anotó Barthes al describir la escritura de Quenau, todas las capas de la escritura: la grafía, el léxico y, especialmente, la elocución (El grado cero 84 ). Este aspecto de su obra revela incluso una peculiar "mirada" del mundo. En términos de Glissant, la escritura y la oralidad concebidas como categorías emergen como vectores opuestos. La escritura estaría vinculada con la trascendencia la inmovilidad corporal y con el despliegue de una forma de pensamiento lineal. En la oralidad en cambio, como la que practica Ana Lydia Vega, el movimiento corporal es producto de la repetición, la redundancia y el predominio del ritmo y todo ello además aparta y anula cualquier versión del absoluto ontológico (40). Es más, sus personajes literarios se reducen a estereotipos para que queden determinados exclusivamente por su lenguaje particular. Así, en su cuento "Letra para salsa y tres soneos por encargo" (Virgenes), la recreación artística no deriva de sus personajes ni de la confección de su trama, ambas reducidas al mínimo, es el regodeo y la exhibición de la adulación excesiva cultivada por "El Tipo" lo que, repetido una y otra vez, estructura el discurso como si se tratara del estribillo de una canción:

Fiel como una procesión de Semana Santa con su rosario de québuena estás, mamichulin, qué bien te ves, qué ricos te quedan esos pantaloncitos, qué chula está esa hembrota, men, qué canto e silán, tanta carne y yo comiendo hueso ... (Vírgenes 83)

También el cierre del cuento, por la singularidad de su confección, desafía toda expectativa del lector con una tríada de versiones todas admisibles, quizá porque en última instancia el desenlace es un aspecto trivial. Es la exuberancia y el exceso de un "mamitólogo" lo que verdaderamente estructura aquí el relato. Esta distorsión del discurso a través de la circularidad y la infatigable repetición del motivo (que tanto identifica a una versión muy fértil de la literatura caribeña), se integran perfectamente en su escritura, como una respiración natural. Así, su adulteración múltiple del lenguaje deja de ser ornamento para convertirse en matriz y motivo de armonía en su literatura.

De la misma forma, la manipulación del lenguaje también permite un propósito exclusivo de despliegue lúdico de significados, por eso se apoya tanto en la parodia, su forma más recurrente de suspender modos de lectura. Como el verdadero demiurgo de su escritura es un gesto oral, esta representación de la elocución se impregna hasta en los dispositivos más tradicionalmente literarios, como puede ser la invocación a las Musas. De forma sintomática este tópico, cargado de ironía irreverente en su obra, más que rogar lucidez a las Musas, reclama únicamente salir indemne: “Archívese el lagrimón. Liquídese la baba. Aquí parqueo, Oh Musa, la carroza esvielá de mis andanzas. Si la Lugo Filippi salió impune de su elegía chauvinista a Ponce, que se me dé la absolución sin penitencia. Vaya". (El tramo ancla 298)

Se permite también hacer explícitas referencias culturales intertextuales llegando incluso a esbozar un personaje a través únicamente de su modelo. Aquí la simulación no sólo sugiere un modelo preestablecido, sino que los atributos o la manera de actuar del personaje quedan figurados únicamente a través de una suma de arquetipos. Así sucede en su obra El tramo ancla donde una mujer para describir la transformación de su marido declara "mi Che Guevara se me pinochetizó" (263). De forma similar, los personajes de "Pasión de Historia" tienen asignado un modelo literario como referente, lo que permite a la escritora manejar la fusión de géneros literarios, principal experimento y escollo en esa obra, con mayores dosis de ironía, dinamismo y complejidad.

Esta escritura en continua metamorfosis (que lejos de reducirse a la imitación de un modelo real siempre se excede con artificio desmesurado) desemboca en composiciones cargadas de densidad conceptual y donde prevalece un continuo cambio de códigos. Ana Lydia Vega señala sobre su propia obra: "Tiendo a la oración corta y muy cargada, hay una preferencia por lo sintético, por decir las cosas rápido y también tengo una predilección por el cierre” (Kerkhoff 593). El relato “Ahí viene Mama Yona” (Vírgenes) es uno de los ejemplos más precisos de esta manera de componer. Aquí la trama del cuento aparece condensada en la primera frase, donde se revela la perturbación y desconcierto que suscita la llegada del personaje estereotipo y simbólico de "Mama Yona" con una imagen carnavalesca: "Cuando Mama Yona amenaza con venir, la casa se vira patas arriba como un perrote buscando cosquillas" (118). De esta forma, la naturaleza paródica confecciona la historia hasta la última frase, el cierre, donde de modo más sentencioso, explícito y rotundo se vuelve a compendiar el relato pero con cambio de código. Aquí, la fascinación para el lector es justamente la ausencia de
Revista Iberoamericana, Vol. LXXIX, Núms. 244-245, Julio-Diciembre 2013, 917-927 ISSN 0034-9631 (Impreso) 
simulación y encubrimiento, una forma de surtir solemnidad al relato: “Ahí viene Mama Yona. A nutrirse de nuestra reverencia. A instalarse plácida y contundente en el nido secular de nuestro miedo" (123). En este cuento encontramos por tanto dos mecanismos muy presentes en su escritura: reiterar y reformular conceptos y la búsqueda constante de una expresión que recapitule, claro reflejo de su estilo aforístico. Este mecanismo discursivo -la adición de una secuencia explícita a una composición aderezada por e tamiz de la ironía- es una clara representación de lo que Freud clasificó como un Witz de tendencia agresiva, es decir, un uso de lo cómico con tintes claramente ideológicos (Freud 17). El mecanismo de la simulación en este caso -la violencia enmascarada por el humor-desaparece y se despliega todo el contenido agresivo de forma explícita para transgredir así su propia escritura.

La continua mudanza de códigos está presente en su obra como un inagotable experimento linguístico. No sólo recrea un determinado lenguaje oral, sino que entrevera registros linguísticos en una perpetua Babel lúdica. Las obras de Ana Lydia Vega también sugieren, como señaló la chilena Diamela Eltit sobre sus propias novelas, una escritora "mestiza, trilingue de mi propio idioma" (Lértora 29). Apropiándonos de un célebre término de Deleuze y Guattari, podríamos hablar aquí de una escritura rizomática (Rizoma 6), es decir, en el afán de búsqueda de una raíz sobre otras raíces, la prioridad deja de ser el presunto absoluto de la identidad de su escritura y lo que cobra verdadero vigor es la naturaleza relacional de esas escrituras. Así, reproduce y rehace modos de conducta subvertidos en un continuo trabajo de desplazamiento que se ejerce sobre la lengua, tal como concebía la libertad en literatura Roland Barthes. Esta es una de las formas de cultivar la simulación de la escritora: la incesante metamorfosis para encubrir y reinventar un modelo, al cual se acerca y se aleja con distanciamiento brechtiano.

Pero sin duda, por albergar todas las versiones de una escritura travestida, el mecanismo de simulación más recurrente en su escritura es la ironía: "seducción y agresión: "voilá" su secreto culinario" (Ferro 6), como la describió la propia Ana Lydia Vega. Se trata por tanto de una escritura especular, concebida en su punto de partida como una reacción, pero que se regodea en su artificio para resultar más efectista. Ahi, entre la estrecha frontera del modelo que se vislumbra en el horizonte y una forma de creación simulada, camuflada, Ana Lydia Vega es capaz de desplegar todo un abanico de posibilidades. La ironía le permite adherir su discurso a paradigmas establecidos y legitimados para incorporar fijeza, suspensión, y desde este enclave suscitar la ruptura con un artificio velado. Como señala la propia escritora sobre el autor literario que se surte de la ironía: "es un tramposo, un embustero consciente que, como todo escritor de ficción pero con mayor descaro, miente para decir su verdad” (Ferro 8). Por esta razón, Ana Lydia Vega compone continuamente personajes estereotipados. Si se concibe el estereotipo como "[...] el rasgo palpable que hace transitar el ornamento inventado hacia la forma canónica, constrictiva, del significado" (Barthes, El Placer del Texto 69), ISSN 0034-9631 (Impreso)

Vol. LXXIX, Núms. 244-245, Julio-Diciembre 2013, 917-927 ISSN 2154-4794 (Electrónico) es en esta mutación donde la escritora mejor puede subvertir significados, por eso sus personajes siempre aúnan todos los rasgos arquetípicos, son estereotipos hiperbólicos. De esta forma Suzie Bermúdez en el relato "Pollito Chicken" sueña con un marido americano con atributos muy concretos, "[...] con un straightAll-American, Republican, church-going, Wall-Street businessman” (Virgenes 76). La parodia de estos estereotipos permite relativizar designaciones categóricas, simular representaciones estáticas y convencionales de la "verdad", a través, no ya de la imitación, sino del exceso del artificio, de una escritura hipertélica, en este caso encarnada en parodia.

Esta subversión-metamorfosis de un modelo-también incluye a la propia figura del escritor y al estilo literario. Es de nuevo el trasunto de la simulación lo que le confiere mayor libertad. Sobre la legitimidad del escritor señala "Quizás ese mismo desamparo económico es lo que paradójicamente le da cachet a las voces que claman en el desierto" (Esperando a Loló 84). Despojar aquí de una aparente dignidad y gravedad al escritor va más allá de una agudeza humorística, es más bien una forma de agredir las certezas y el beneplácito de las formas de conocimiento y los bienes especulativos. La actitud de su estilo literario también busca refutar el mito de la solemnidad del escritor, en este caso se trata en última instancia de reaccionar ante la literatura puertorriqueña que la precede y, al mismo tiempo, reconstruir y desplegar una identidad del escritor nacional, especialmente sobre "Los cuatro jinetes del Apocalipsis", como ella denomina a René Marqués, Emilio Díaz Valcárcel, Pedro Juan Soto y José Luis González. ${ }^{3}$ El cambio de estilo entre unos y otros (integrado en una renovación generacional) no es simplemente una nueva alternativa ornamental, va mucho más allá. Aunque el principio teleológico es similar en todos ellos, en Ana Lydia Vega ya se percibe un cambio de episteme que altera toda la escritura. Por tanto, en ese saber implícito de carácter sistemático que conforma tanto el apriori histórico como las condiciones de posibilidad de acciones y pensamientos, lo que marca la verdadera variante entre unos y otros no es tanto lo que han pensado o imaginado sino lo "no-pensado", que desde el comienzo de la creación los sistematiza:

No tenemos que demostrarle a nadie nuestro derecho al español. Podemos jugar, subvertir, desmitificar, mezclar inglés y español, jerga culta y popular, buenas y malas palabras, multiplicando la saludable irreverencia que se prohibían a sí mismos la gran mayoría de los escritores de pasadas generaciones. (Esperando a Loló 89)

En la periodización de la literatura puertorriqueña, como en la mayoría de las hispánicas, también se advierte un canon basado en el principio de clasificación generacional. Como señaló de forma aguda el crítico José Carlos Mainer al referirse a la literatura contemporánea española: "en su predominio coinciden dos cosas: por un lado, la noción aceptada de que la evolución literaria es un permanente sistema de movilizaciones, asentamientos y resquebrajamientos cíclicos; por otro, la remisión de las causas de tales cambios a una mezcla nunca demasiado clara de determinaciones históricas más o menos conscientes y de necesidades colectivas de definición" (Mainer, Historia, literatura, sociedad 276).

Revista Iberoamericana, Vol. LXXIX, Núms. 244-245, Julio-Diciembre 2013, 917-927 ISSN 0034-9631 (Impreso) ISSN 2154-4794 (Electrónico) 
Por eso, la distorsión y la tendencia lúdica de su escritura son fundamentales para desentrañar los mecanismos de su discurso literario. Su frase sentenciosa y epigramática, la seducción de las palabras como juego o el dispositivo de la simulación no anulan la querencia crítica o su actitud militante, pero sí denotan una relación más festiva con las ideas. Hay ahora "una aguda conciencia del ridículo, que viene del desinflamiento de las pretensiones mesiánicas, la desconfianza de los discursos enlatados y la aceptación de la relatividad de toda perspectiva" (Esperando a Loló 104) que marca los cauces de una nueva forma de escribir.

Sin embargo, su estilo locuaz y festivo no se propaga en una versión exuberante lejos de ello, muestra siempre una predilección por lo sintético que impregna incluso su forma de reflexionar. Los conceptos en su escritura, de hecho, son descritos o definidos a través de su habilidad aforística para recurrir a una dualidad que se complementa. Todo concepto se puede descomponer así en un pensamiento binario. De esta forma, la ironía es para nuestra escritora un "coito febril entre el horror y el humor" (Ferro 3), o bien la suma de "seducción y agresión" (Ferro 6). La evolución histórica de la literatura puertorriqueña se puede condensar en "Del nacionalismo hard-core al populismo light" (Ferro 3), y lo mismo sucede con su estilo, donde la frase sentenciosa está sometida paradójicamente, a una constante reformulación. ${ }^{4}$ Esta es por tanto la gran novedad de su estilo: aquí la subversión y mezcla de las palabras, la simulación como mecanismo compositivo o la recreación del lenguaje oral están inscritos en un estilo codificador y sintético, lo que se podría denominar retórica cartesiana, presente incluso hasta en momentos de formas antilineales de narración, como puede ser la tríada de finales alternativos en el relato de "Letra para salsa y tres soneos por encargo" (Vírgenes).

No hay duda por todo ello de que la escritura en la obra de Ana Lydia Vega es estratégica y está totalmente premeditada. El componente lúdico que se desprende de ella no es consecuencia de un discurso liviano e insustancial. Su mecanismo de simulación más recurrente, la parodia, es proclamada sólo en un campo de tensiones implícitas o latentes, aunque aquí la forma de movimiento que describe tales tensiones no es la de embate formal, sino la de un fluir aparentemente ocioso. Es más, tras el dispositivo de su escritura travestida y su irreverencia festiva emerge una aguda mirada crítica, pero representa ya una mirada claramente posmoderna, es decir, la crítica se hunde también sobre la certeza epistemológica y el discurso ortodoxo. Esta es la gran diferencia con la generación de escritores que la precede para abordar, sin embargo, obsesiones comunes.

${ }^{4}$ Como muy bien ha señalado recientemente Néstor García Canclini, la libertad del artista, mayor que la de un científico social, le permite expresar con "metáforas" condensaciones e incertidumbres de sentido que no encontramos cómo formular en "conceptos", lo que debería implicar reconsiderar las articulaciones entre estos dos modos de abarcar lo que se nos escapa en el presente. (Néstor García Canclini (2010). La sociedad sin relato. Antropología y estética de la inminencia. Madrid: Katz, 47). Sin duda, los ensayos de Ana Lydia Vega son un buen ejemplo de esta potencialidad que observa García Canclini.

Revista Iberoamericana, Vol. LXXIX, Núms. 244-245, Julio-Diciembre 2013, $917-927$ ISSN 0034-9631 (Impreso) ISSN 2154-4794 (Electrónico)
No se trata de alterar la finalidad última, sino que, como señala Umberto Eco: "la respuesta posmoderna a lo moderno consiste en recalcar que el pasado, al que no se puede destruir porque su destrucción conduce al silencio, ha de ser irónicamente visitado de nuevo, de manera no inocente" (Compagnon 115). No es casual de hecho que la cita que abre el relato de Ana Lydia Vega en "Sobre Tumbas y héroes (Folletín de caballería boricua)" sea “...And for memory I had substituted inquiry” de George Lamming. El relato, con las coordenadas habituales de ironía, exhibe la tensión dialéctica entre dos personajes, el joven Emanuel Meléndez que:

[...] exhibe sin pudor su pasión de historia, no la historia cipaya de los administradores coloniales, no, ni la de las mediocres maldades de metrópolis madrastras...Sino la Intra-Historia, la épica oculta, la canción de gesta de los supuestamente derrotados. Aquí, intermedio respiratorio para que Don Virgilio ejerza un derecho al aplauso que no ejerce. Viene entonces el tema obligado: la importancia revolucionaria de los líderes asesinados, su identidad netamente antillana, Bauren dominicano $[\ldots]$ su envergadura trans-secular, su carácter absolutamente científico, su interés cuasi-detectivesco [...] (Pasión de historia y otras historias de pasión 107)

El viejo Don Virgilio sin embargo reacciona ante Emanuel con otra metodología: "habrá que darle "ciencia' para que tome conciencia" (109), y en este caso la "ciencia", el gran procedimiento, consistirá en una invocación a los muertos. Este cuento sobre la memoria histórica, engarzado en un relato de misterio, se solventa de forma paródica, con una reencarnación. La parodia juega aquí con uno de los rasgos más sustanciales de la posmodernidad: la doctrina nietzschiana del eterno retorno. Como señala Vattimo "al intentar sustraerse a las lógicas del desarrollo de la modernidad, y muy especialmente a la idea de una 'superación' crítica en aras de una nueva fundación, [Lo posmoderno] retoma la búsqueda emprendida por Nietzsche y Heidegger en su relación 'crítica' con el pensamiento occidental” (Compagnon 119). Se vislumbra así cómo toda la obra de Ana Lydia Vega está entreverada de parodia. En todos sus textos fluye -en alguna de sus múltiples versiones- una función especular detentada a través del mecanismo de la simulación y estimulada con alguna agudeza. Se puede precisar, por tanto, cómo la escritura de esta autora, considerada en múltiples ocasiones quintaesencia de la posmodernidad, no decae en la práctica del pastiche, como sentenciaba Jameson al juzgar el período (Teoría de la postmodenidad 38), sino que, en su caso, la máscara lingüística, sus coordenadas de parodia, no amputan un desbordante impulso satírico.

Tras estas estrategias discursivas hay un compromiso con el desembarazo, la autonomía y la libertad de creación. Al rechazar el lance trascendente de la búsqueda de algún fin de abstracción sublime - exigencia que asume sin embargo la generación de escritores que le precede- el escritor dispone de una nueva libertad y una osadía lúdica que revitaliza el texto y lo dispone de un aparente desorden y un continuo alzamiento

Revista Iberoamericana, Vol. LXXIX, Núms. 244-245, Julio-Diciembre 2013, 917-927 ISSN 0034-9631 (Impreso) ISSN 2154-4794 (Electrónico) 
sobre el discurso ortodoxo. Es por tanto el dispositivo de simulación, un trasunto de cualquier versión literaria, lo que permite propagar las posibilidades de lectura de su obra. Sin embargo, este espíritu de transgresión no debe ensombrecer una forma de escritura estratégica y rigurosa. En primer lugar porque, dentro de un diorama de vertientes, Ana Lydia Vega encara la obra creativa como un problema puramente técnico o como e ejercicio de unas facultades acrisoladas. Simultáneamente, esta escritura hipertélica es la membrana precisa de unas obras que aparentan siempre integrar las dos partes que Francis Bacon distinguía en la argumentación: una idea negativa, pars destruens, que la autora formula en términos de radical cuestionamiento y crítica, y en torno a una idea más cosntructiva, pars construens, como un nuevo espacio reflexivo, pero donde la idea tradicional de sujeto se transmuta en máscara. La matriz de su estilo por tanto, una escritura hipertélica, impide cualquier cerco en su lectura y la aparente composición liviana de su escritura encubre sin embargo un arma arrojadiza. Se puede observar as cómo los textos de esta autora puertorriqueña no agotan jamás su fuerza de significación. Eso sí, hay que procurar que fluyan con libertad esas relaciones complejas, sutiles versátiles, anudadas entre las formas propias de las obras, abiertas en diferente grado a las apropiaciones, y los hábitos o preocupaciones de sus diferentes públicos, como certeramente describió hace unos años el francés Roger Chartier (22).

\section{OBRAS CITADAS}

Bacon, Francis. Novum Organum. Cristóbal Litrán, trad. Barcelona: Ediciones de Bolsillo, 1979.

Barthes, Roland. El placer del texto y lección inaugural de la cátedra de semiología literaria del collège de frances. Nicolás Rosa y Óscar Terán, trads. Buenos Aires: Siglo XXI Editores Argentina, 2004

El grado cero de la escritura: seguido de nuevos ensayos críticos. Nicolás Rosa, trad. Buenos Aires: Siglo XXI, 2003.

Compagnon, Antoine. Las cinco paradojas de la modernidad. Julieta Fombona, trad. Caracas: Monte Ávila Editores, 1991.

Chartier, Roger. El orden de los libros: lectores, autores, bibliotecas en Europa entre los siglos XIV y XVIII. Ana Roda, trad. Barcelona: Gedisa, 1994.

Deleuze, Gilles y Félix Guattari. Kafka, por una literatura menor. Jorge Aguilar, trad. México: Ediciones Era, 1999

Rizoma. Introducción. José Vázquez Pérez y Umbelina Larraveleta, trads. Valencia: Pre-Textos, 2005

Ferro, Roberto (ed.). La parodia en la literatura latinoamericana. Buenos Aires: Universidad de Buenos Aires, 1993.

Freud, Sigmund. El chiste y su relación con lo inconsciente. Luis López Ballesteros, trad. Madrid: Alianza Editorial, 1970.

Revista Iberoamericana, Vol. LXXIX, Núms. 244-245, Julio-Diciembre 2013, 917-927 ISSN 0034-9631 (Impreso) ISSN 2154-4794 (Electrónico)
Glissant, Édouard. Introducción a una poética de lo diverso. Luis Cayo Pérez, trad. Barcelona: Ediciones del Bronce, 2002.

González, Aníbal. “Ana Lydia Pluravega: unidad y multiplicidad caribeñas en la obra de Ana Lydia Vega". Revista Iberoamericana LIX/162-163 (1993): 289-300.

Guillory, John. "Canon". Critical Terms for Literary Study. Frank Lentricchia y Thomas McLaughlin, eds. Chicago: The U of Chicago P, 1995. 233-250.

Kerkhoff, Manuela. "Entrevista con Ana Lydia Vega". La Torre 9/36 (1995): 573-610.

Lértora, Juan Carlos. Una poética de literatura menor: la narrativa de Diamela Eltit. Santiago de Chile: Editorial Cuarto Propio, 1993.

Mignolo, Walter. "Los cánones y (más allá de) las fronteras culturales (o ¿de quién es el canon del que hablamos?)”. El canon literario. Enric Sullá, comp. Madrid: Arco-Libros, 1998. 237-270.

Said, Edward. El mundo, el texto y el crítico. Ricardo García Pérez, trad. Barcelona: Debate, 2004

Cultura e Imperialismo. Nora Catelli, trad. Barcelona: Anagrama, 1996.

Sarduy, Severo. Obra completa. Madrid: ALLCA XX, 1999.

Sotomayor, Aurea María. Hilo de Aracne. Literatura puertorriqueña hoy. Río Piedras Universidad de Puerto Rico, 1995.

Vega,Ana Lydia. El tramo ancla. Ensayos puertorriqueños de hoy. Río Piedras: Editorial de la Universidad de Puerto Rico, 1991.

Pasión de historia y otras historias de pasión. Buenos Aires: Ediciones de la Flor, 1987.

Esperando a Loló y otros delirios generacionales. Río Piedras: Universidad de Puerto Rico, 1994.

y Carmen Lugo Filippi. Virgenes y mártires. Puerto Rico: Editorial Cultural, 2002.

Iberoamericana, Vol. LXXIX, Núms. 244-245, Julio-Diciembre 2013, 917-927 ISSN 0034-9631 (Impreso) ISSN 2154-4794 (Electrónico) 
